\title{
Effect of 1-Butyl-3-Methylimidazolium Tricyanomethane in Extractive Desulphurization Process on Model Oil
}

\section{Syamsul B. Abdullah'1*, Mohd Amirul Mukmin Abdullah'1, and Z. Man²}

${ }^{1}$ Faculty of Chemical and Process Engineering Technology, Universiti Malaysia Pahang, Lebuhraya Tun Razak, 26300 Gambang, Pahang. 2PETRONAS lonic Liquid Centre, Chemical Engineering Department,Universiti Teknologi PETRONAS, Bandar Seri Iskandar, 31750 Tronoh, Perak

\begin{abstract}
Driven by regulatory requirements to reduce the content of sulphur in fuels, the demand to find an alternative process to hydrodesulphurization is on the rise. In this study, experiments were conducted for the removal of sulphur compound (present as benzothiophene or BT) with concentration of $2000 \mathrm{ppm}$ in the model oil (present as n-dodecane or n-C12) using 1 butyl-3-methylimidazolium tricyanomethane ([bmim][TCM]) as the extractant. The effects of stirring speed, extraction time and water content on the extraction efficiency were investigated. In the end, the loading factor of the [bmim] [TCM] is also discussed where it can be concluded that, more than one mole of [bmim][TCM] may interacted with one mole of BT during extractive desulphurization process.
\end{abstract}

\author{
KEYWORDS \\ Extractive \\ desulphurization, \\ sulphur removal, \\ ionic liquids, \\ model oil, \\ [Bmim][TCM]
}

\section{INTRODUCTION}

The main goal In every oil refinery, the central separation step is distillation process where petroleum is separated into various fractions according to their volatility. Unfortunately, the sulphur compounds present in the crude oil will also be collected in the fractionated distillation products. In order to meet market regulation, the sulphur content in each product obtained from different fractionation temperatures is required to be removed. For commercial diesel especially, due to the tightening of air quality act all over the world, the maximum allowable limit of sulphur content has been reduced drastically (Zhao et al. 2007; Dai et al. 2008; Liu et al. 2008).

For instance, European Union (EU) imposed a restriction on sulphur content in fuels at $350 \mathrm{ppm}$ in 2004, followed by a drastic reduction to $50 \mathrm{ppm}$ in 2006, when later reduced it further to $10 \mathrm{ppm}$ in 2010. In general, after 2010, the limit for sulphur content in fuel has been reduced to within the range of 15 to $10 \mathrm{ppm}$ in Japan, United States of America (USA), Canada, Australia, New Zealand, Singapore and Hong Kong. Currently, many of the other countries in the world, especially those with high fuel consumption such as China, India, Russia, Brazil and Iran, are taking steps to follow the standard fuel product specification that is presently in place in the USA and Europe. Some countries in Asia, Middle East and South America such as Thailand, Bahrain, Oman, Kuwait, Argentina, Chile and Peru are currently contemplating a more drastic action in ratcheting down the standards which would bring them at par with the USA Environmental Protection Agency (EPA) and Euro IV standard, where the limit for sulphur content is 50 ppm (Lo et al. 2003; Lu et al. 2007; Rheinberg et al. 2008; Zhao et al. 2008; Li et al. 2009; Adzamic et al. 2009; Kulkani and Afonso, 2010; Taib and Murugesan, 2011; Wang et al. 2011).

In Malaysia, since 2006 petroleum companies have adopted Euro II standard where the sulphur content is kept at 500 $\mathrm{ppm}$. However, due to stringent environmental requirement imposed by the government recently, petroleum refineries are forced to comply with a new requirement to further reduce the sulphur content up to $50 \mathrm{ppm}$ in accordance to Euro IV requirement which will commence in 2015 (ACFA, 2012).

ILs are made up of at least two components namely cation and anion. The most commonly used cations in ILs is imidazolium whereas most popular anions are BF4 and PF6. Imidazoles are favorable species for investigation because of their stability towards air and water, ability to stay in liquid form over a wide range of temperature and their relatively favorable density and viscosity.

Although various kinds of ILs have been used as extractive solvent, their direct applications for sulphur removal have not been extensively studied due to lack of information on the behavior of ILs itself. This also hampers efforts in designing and selecting appropriate ILs for extractive desulphurization of fuels which needs to be addressed before possible applications such as desulphurization of petroleum products can be implemented (Davis and Forrester, 1999; Tian et al. 2007; Liu et al. 2008). Taking this into consideration, the present study investigated the behavioral of ILs in n-C12. 


\section{MATERIALS AND METHODS}

In this study, all extraction experiments were conducted using batch system in atmospheric environmental. The $25 \mathrm{~mL}$ extractor was filled with known amounts of BT (sulphur compound) in n-C12 (major component in fuels especially diesel) as the model oil. The extractor's cap was fabricated to install the thermometer in order to measure temperature during the extraction process. Due to the hygroscopic nature of ILs, the water content of all ILs were checked before using in the extraction process. If the measured water content of ILs is higher than 500ppm, the ILs was dried in a vacuum oven and its water content re-determined before proceeding for extraction.

During the extractive desulphurization process, the mixture of ILs and model oil was stirred at a desired speed and time to attain equilibrium at atmospheric conditions. The two layers were observed. The ILs, which usually having higher density than the model oil, form the lower phase. Thus, the upper phase, which is model oil, could be easily withdrawn for quantitative assay analysis of BT in model oil phase using high performance liquid chromatography (HPLC). The HPLC (HP1100, Agilent, US) was equipped with an auto-sampler, a reverse-phase Zorbax SB-C18 column (4.6 mm X $150 \mathrm{~mm} ; 5 \mu \mathrm{m})$ and a diode array detector (DAD). Detail of the HPLC analysis conditions is shown in Table 1 . The external standard method at 280nm was used to quantify BT composition the oil phase. Agilent 1200 Series LC software was used for system programming and data retrieval. Based on the measured values, the material balance of BT in model ILs phase was made.

Table 1. Analytical conditions for HPLC analysis.

\begin{tabular}{ll}
\hline & Description \\
\hline Flow rate & $0.7 \mathrm{ml} /$ min \\
Mobile phase & $90 \%$ methanol in water $(\mathrm{v} / \mathrm{v} \%)$ \\
Oven temperature & $40^{\circ} \mathrm{C}$ \\
Injection volume & $10 \mu \mathrm{L}$ \\
\hline
\end{tabular}

The composition of BT (sulphur compound) in model oil determined by HPLC analysis was then used to calculate the partition coefficient, Kd which defines the extent of the mobility of BT into ILs phase using the following relationships:

$$
K_{d}=\frac{[C]_{s, I L}}{[C]_{s, M O}}
$$

where, $[\mathrm{C}] \mathrm{s}, \mathrm{IL}$ is the concentration of BT in the ILs phase after extraction (ppm) and [C]s,MO is the concentration of BT in the model oil phase after extraction (ppm).

The effect of three process variables namely stirring speed, extraction time and water content was studied. The optimum value of each variable was then further used in the study.

\section{EXPERIMENTAL RESULTS}

The effect of stirring speed on sulphur extraction efficiency ( $K_{d}$ value) was firstly investigated. As shown in Figure 1 , there is a drastic extraction efficiency increment with an increase of stirring speed from stagnant to $100 \mathrm{rpm}$. A very low extraction occurred during the stagnant period where only interfacial extraction of both oil and ILs took place. Then the $K_{d}$ value continued to linearly increase with the increase of stirring speed from $100 \mathrm{rpm}$ to $500 \mathrm{rpm}$. The maximum allowable speed of the extractor vial is $500 \mathrm{rpm}$, therefore the experiment was limited up to $500 \mathrm{rpm}$ as the optimum stirring speed in order to achieve higher sulphur extraction efficiency.

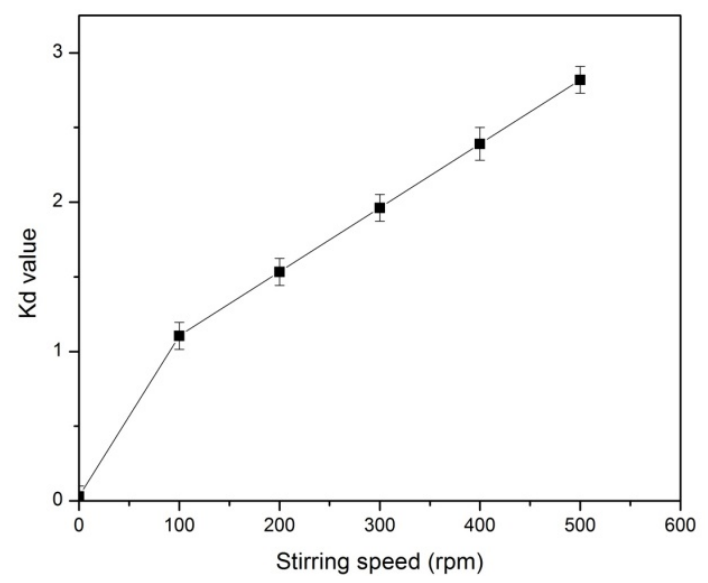

Figure 1. The effect of stirring speed on sulfur extraction efficiency (Kd value) by [bmim][TCM]. (Conditions: Extraction time - $10 \mathrm{~min}$, mass ratio ILs/model oil - 1/1, room temperature, initial BT concentration in model oil 2000 ppm). 
In an effort to understand the effect of extraction time, experiments were repeated at the optimum stirring speed condition and the results are displayed in Figure 2. As can be seen from Figure 2, the sulphur extraction efficiency increased with an increase in extraction time for the first 30 minutes. Extending the extraction time longer than 30 minutes did not result in extracting more BT from the model oil phase, indicating that the extraction process has reached equilibrium state. Similar results were obtained by other researchers, where the required extraction time ranged from 25 min to $30 \mathrm{~min}$ [Liu et al. 2008; Taib and Murugesan, 2011]. It was also observed that there is no marginal increase in extraction efficiency by increasing the extraction time of unstirred samples.

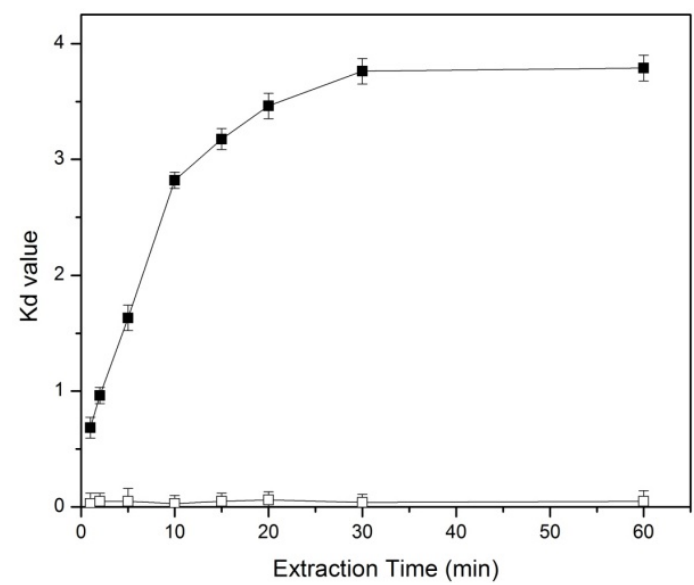

Figure 2. The effect of extraction time on sulfur extraction efficiency (Kd value) by [bmim][TCM] (Conditions: Stirring speed - $500 \mathrm{rpm}$, mass ratio ILs/model oil - 1/1, room temperature, initial BT concentration in model oil $2000 \mathrm{ppm})$

As shown in Figure 3, the sulphur extraction efficiency decreased dramatically as the water content in [bmim][TCM] increased, for instance $2.5 \%$ of water content in [bmim][TCM] can drop the $\mathrm{K}_{\mathrm{d}}$ value by about 1.5 from 3.672 at $0.000233 \%$ (233 ppm) water content. This implies that the efficiency of BT extraction using [bmim][TCM] from the model oil decreases drastically with the presence of more water in [bmim][TCM]. On the other hand, this also suggests that the sulphur compounds dissolved in the spent ILs can be regenerated by water dilution process, which will be later discussed.

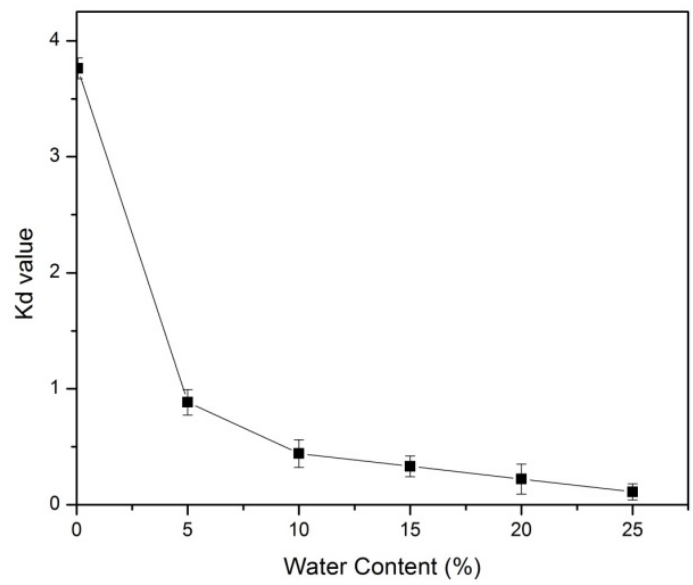

Figure 3. The effect of water content on sulfur extraction efficiency (Kd value) by [bmim][TCM]. (Conditions: Stirring speed - $500 \mathrm{rpm}$, extraction time - $30 \mathrm{~min}$, mass ratio ILs/model oil - 1/1, room temperature, initial BT concentration in model oil-2000 ppm).

The choice of a suitable composition for the ILs (extractant) was carried out experimentally, and [bmim][TCM] was chosen. The effect of [bmim][TCM] concentration in water, as the extracting solvent, on sulphur extraction efficiency is shown in Figure 4. A drastic reduction in $\mathrm{K}_{\mathrm{d}}$ value can be seen as the [bmim][TCM] concentration dropped from 4.36 $\mathrm{mM}$ to $4.14 \mathrm{mM}$; but, from $3.93 \mathrm{mM}$ down to $3.27 \mathrm{mM}$ of [bmim][TCM] concentration, the $\mathrm{K}_{\mathrm{d}}$ value was linearly reduced. This suggests that at the initial stage of extraction process, which shows major influence toward extraction efficiency, the presence of water in [bmim][TCM] should be avoided. In the presence of both water and BT, the interaction of ILs is much more favourable for water instead of BT via hydrogen bonding, by means a stronger interaction than $\pi-\pi$ bonding. 




Figure 4. Relationship between $\mathrm{Kd}$ value and [bmim][TCM] concentration.

In the case of loading factor, when $\mathrm{R}>1$ it is called overloading. It means that more than two moles of solutes (represented by BT) react with one mole of extractant (represented by [bmim][TCM]). On the other hand, in the case of $\mathrm{R}<1$, it means that several mole of extractant interact with one mole of solute [Yunhai et al. 2006]. As seen in Figure 5, at any point the $\mathrm{R}$ values for BT extraction is lower than 1 . This indicates that more than one mole of [bmim][TCM] may interacted with one mole of BT during the extractive desulphurization process.

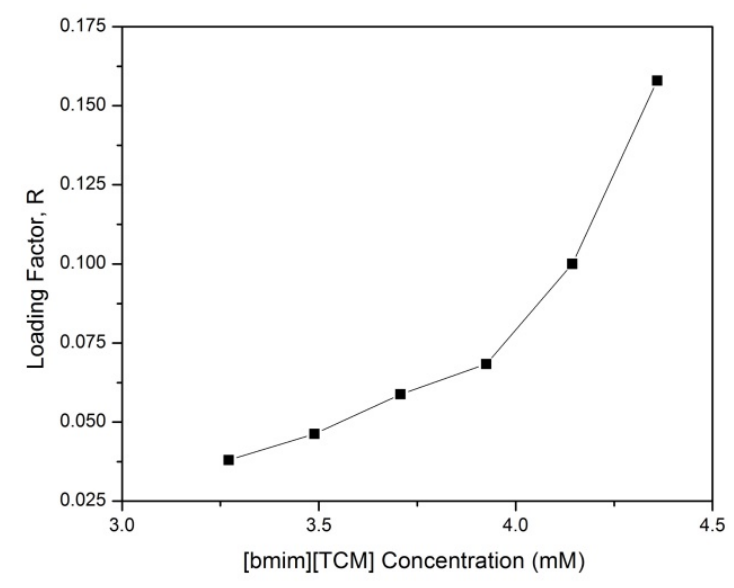

Figure 5. Relationship between loading factor and initial concentration of [bmim][TCM] (Conditions: Stirring speed $500 \mathrm{rpm}$, extraction time - $30 \mathrm{~min}$, mass ratio ILs/model oil - 1/1, room temperature, initial BT concentration in model oil-2000 ppm).

\section{CONCLUSION}

The study on the effect of stirring speed and extraction time on the performance of extractive desulphurization using model oil for [bmim][TCM] showed that increasing the stirring speed contributed to increase the desulphurization performance. On the other hand, an optimum extraction time was observed, whereby in this work the optimum extraction time was 30 minutes at the maximum stirring speed of $500 \mathrm{rpm}$. Again it should be mentioned here that the maximum stirring speed in this work is limited by the equipment limit. Extending the extraction time longer than 30 minutes did not result any significant removal of sulphur compounds from the model oil. Another factor that affects desulphurization performance is water content in ILs. The water content should be minimized as low as possible in order to optimize the desulphurization performance.

\section{REFERENCES}

Adzamic, T., Sertic-Bionda, K., Zoretic, Z. (2009). Desulfurization of FCC gasoline by extraction with sulfolane and furfural. NAFTA Journal, 60, 485-90

Dai, W., Zhou, Y., Wang, S., Su, W., Sun, Y., Zhou, L. (2008). Desulfurization of transportation fuels targeting at removal of thiophene/benzothiophene. Fuel Processing Technology, 89, 749-55

Davis, J.H.J. and Forrester, K.J. (1999). Thiazolium-ion based organic ionic liquids (OILs): novel OILs which promote the benzoin condensation. Tetrahedron Letters, 40, 1621-2

Kulkarni, P.S. and Afonso, C.A.M. (2010). Deep desulfurization of diesel fuel using ionic liquids: current status and future challenges. Green Chemistry, 12, 1139-49 
Li, H., He, L., Lu, J., Zhu, W., Jiang, X., Wang, Y., Yan, Y. (2009). Deep oxidative desulfurization of fuels catalyzed by phosphotungstic acid in ionic liquids at room temperature. Energy \& Fuels, 23, 1354-7

Liu, D., Gui, J., Song, L., Zhang, X., Sun, Z. (2008). Deep desulfurization of diesel fuel by extraction with task-specific ionic liquids. Petroleum Science \& Technology, 26, 973-82

Lo, W., Yang, H., Wei, G. (2003). One-pot desulfurization of light oils by chemical oxidation and solvent extraction with room temperature ionic liquids. Green Chemistry, 5, 639-42

Lu, L., Cheng, S., Gao, J., Gao, G., He, M. (2007). Deep oxidative desulfurization of fuels catalysed by ionic liquid in the presence of $\mathrm{H}_{2} \mathrm{O}_{2}$. Energy \& Fuels, 21, 383-4

Rheinberg, O. V., Lucka, K., Kohne, H., Schade, T., Andersson, J.T. (2008). Selective removal of sulphur in liquid fuels for fuel cell applications. Fuel, 87, 2988-96

Taib, M.M. and Murugesan, T. (2011). Experimental study on the extractive desulfurization of model fuel using hydroxyl ammonium ionic liquids. Asia-Pacific Journal of Chemical Engineering

Tian, L., Cao, F., Fang, D., Guo, S. (2007). Alkylation of toluene with 1,3-pentadiene over [bupy]BF4 - AlCl3 ionic liquid catalyst. Chinese Journal in Chemical Engineering, 15, 680-2

Wang, X., Han, M., Wan, H., Yang, C., Guan, G. (2011). Study on extraction of thiophene from model gasoline with Bronsted acidic ionic liquids. Frontiers on Chemical Science \& Engineering, 5, 107-12

Yunhai, S., Houyong, S., Deming, L., Qinghua, L., Dexing, C., Yongchuan, Z. (2006). Separation of glycolic acid from glycolonitrile hydrolysate by reactive extraction with tri-n-octylamine. Separation \& Purification Technology, 49, 20-6

Zhao, D., Wang, J., Zhou, E. (2007). Oxidative desulfurization of diesel fuel using Bronsted acid room temperature ionic liquid in the presence of $\mathrm{H} 2 \mathrm{O} 2$. Green Chemistry, 9, 1219-22

Zhao, D., Sun, Z., Li, F., Liu, R., Shan, H. (2008). Oxidative desulfurization of thiophene catalyzed by (C4H9)4NBr·2C6H11NO coordinated ionic liquid. Energy \& Fuels, 22, 3065-9 